\title{
Monoalkylcarbonate Formation in the System Monoethanolamine-Water-Carbon Dioxide
}

\author{
Richard Behrens, Elmar Kessler, Kerstin Münnemann, Hans Hasse, Erik \\ von Harbou ${ }^{1, *}$ \\ Laboratory of Engineering Thermodynamics (LTD), Technische Universität \\ Kaiserslautern, Erwin-Schrödinger-Straße 44, Kaiserslautern, 67663, Germany
}

\begin{abstract}
In a recent study, we have shown by NMR spectrocopy that monoalkylcarbonates are formed in substantial amounts in aqueous solutions of the tertiary alkanolamine methyldiethanolamine (MDEA) upon loading with carbon dioxide $\left(\mathrm{CO}_{2}\right)$. These species had been overlooked by most authors previously. In the present work, this study was extended to the primary alkanolamine monoethanolamine (MEA). Also here monoalkylcarbonates were found, but only at $\mathrm{CO}_{2}$ loadings above $0.5 \mathrm{~mol} \mathrm{CO}_{2}$ per mol MEA. Both the amine and its carbamate form monoalkylcarbonates. The concentration of the monoalkylcarbonates was determined with ${ }^{13} \mathrm{C}$ NMR spectroscopy in a wide range of $\mathrm{CO}_{2}$ loadings, MEA concentrations, and temperatures. Based on this comprehensive data the chemical equilibirium constants of the formation of the monoalkylcarbonates were determined.
\end{abstract}

Keywords: Reactive absorption of $\mathrm{CO}_{2}$, Chemical equilibrium constants, ${ }^{13} \mathrm{C}$ NMR spectroscopy, Monoethanolamine, Monoalkylcarbonate

\footnotetext{
${ }^{*}$ Corresponding author Email address: erik.vonharbou@mv.uni-kl.de (Erik von Harbou)

${ }^{1}$ Current affiliation: BASF SE, Ludwigshafen am Rhein, 67063, Germany
} 


\section{Introduction}

Recently, we identified and quantified monoalkylcarbonates in aqueous solutions of the tertiary alkanolamine methyldiethanolamine (MDEA) loaded with carbon dioxide $\left(\mathrm{CO}_{2}\right)$ at temperatures between 293-333 K [1]. At those temperatures, about 10 mol \% of the absorbed $\mathrm{CO}_{2}$ are bound in monoalkylcarbonates at all $\mathrm{CO}_{2}$ loadings. Unlike tertiary alkanolamines, primary and secondary alkanolamines form carbamates with $\mathrm{CO}_{2}$. Yamada et al. [2] have shown that despite the formation of carbamates, monoalkylcarbonates can also be found in $\mathrm{CO}_{2}$ loaded aqueous solutions of 2-(ethylamino)ethanol, a secondary alkanolamine. Hence there was reason to believe that monoalkylcarbonates are formed also in $\mathrm{CO}_{2}$ loaded aqueous solutions of primary alkanolamines like monoethanolamine (MEA). Very recently, Cieslarova et al. [3] came to the same conclusion and looked for monoalkylcarbonates in the system $\mathrm{MEA}-\mathrm{H}_{2} \mathrm{O}-\mathrm{NaHCO}_{3}$ with ${ }^{13} \mathrm{C}$ NMR spectroscopy. They found a peak at high ${ }^{13} \mathrm{C}$ chemical shifts, which they assigned to the monoalkylcarbonate of MEA. Moreover, Cieslarova et al. [3] assumed that ${ }^{13} \mathrm{C}$ NMR peaks in the system $\mathrm{MEA}-\mathrm{H}_{2} \mathrm{O}-\mathrm{CO}_{2}$, which were assigned by Jakobsen et al. [4] to impurities, are in fact monoalkylcarbonates of MEA and of the carbamate of MEA. However, Cieslarova et al. [3] neither conducted a thorough peak identification nor a structure elucidation and did not discuss the presence of 1,3-Oxazolidin-2-one (named here as oxazolidone).

It is worthwhile discussing the presence of oxazolidone as its formation was stated by several authors [5] 8 . It is assumed that this species plays an important role in the degradation of MEA. For example, Talzi and Ig- 
nashin [5] analyzed aqueous solutions of MEA taken from various stages of an industrial gas treatment facility and identified species, which they stated to be reaction products of the conversion of oxazolidone. Under laboratory conditions, the formation of oxazolidone in the system $\mathrm{MEA}-\mathrm{H}_{2} \mathrm{O}-\mathrm{CO}_{2}$ is assumed to take up to eight weeks and occurs at temperatures between 373$423 \mathrm{~K}$ [7]. In the presence of additional species like carbonyl sulfide (COS) or $\mathrm{Fe}_{2}{ }^{+}$ions, the formation of oxazolidone is reported to be faster and to occur at moderate temperatures [5, 8]. In freshly prepared solutions, at moderate temperatures, in the absence of additional species, the formation of oxazolidone is normally not observed in the system MEA- $\mathrm{H}_{2} \mathrm{O}-\mathrm{CO}_{2}$ [5]. Even though these conditions were fulfilled in the study of Böttinger et al. [6], these authors assumed that some unknown peaks in their ${ }^{13} \mathrm{C}$ NMR spectra were caused by oxazolidone.

In this work, the composition of the liquid phase in $\mathrm{CO}_{2}$ loaded aqueous solutions of MEA was investigated by NMR spectroscopy with a special focus on the thorough elucidation of all species existent in the liquid phase. By means of two-dimensional NMR techniques, the presence of the monoalkylcarbonate of monoethanolamine (2-ammonioethyl carbonate) and the monoalkylcarbonate of the carbamate of monoethanolamine (2(carboxylatoamino)ethyl carbonate) was proven. It was furthermore shown that the NMR peaks, which were assigned by Böttinger et al. [6] to oxazolidone, result from the monoalkylcarbonate of MEA. The experimental results show that at $\mathrm{CO}_{2}$ loadings above $0.5 \mathrm{~mol} / \mathrm{mol}$ about $10 \mathrm{~mol} \%$ of the $\mathrm{CO}_{2}$ is bound in monoalyklcarbonates. To enable the correct description of the composition of the liquid phase even at high $\mathrm{CO}_{2}$ loadings, an exist- 
ing thermodynamic model of the system $\mathrm{MEA}-\mathrm{H}_{2} \mathrm{O}-\mathrm{CO}_{2}$ was extended so that it includes the formation of the monoalkylcarbonate of MEA and of the monoalkylcarbonate of the carbamate of MEA.

Experiments were carried out to determine the chemical equilibrium constants of the formation of the monoalkylcarbonates. The chemical equilibria constants of the other reactions were taken from Wagner et al. [9]. The strong thermodynamic nonidealities in the liquid phase was accounted for using an extended version of Pitzer's model as described by Wagner et al. [9]. The new model is able to predict the formation of monoalkylcarbonates and thus of all species present in the system $\mathrm{MEA}-\mathrm{H}_{2} \mathrm{O}-\mathrm{CO}_{2}$ in the temperature range 293-313 K. Moreover, this study shows that no oxazolidone is formed at moderate temperatures, and in the absence of additional substances, when $\mathrm{CO}_{2}$ loaded aqueous solution of MEA are stored only for a short time.

\section{Reaction System}

Figure 1 shows an exemplary ${ }^{13} \mathrm{C}$ NMR spectrum of the liquid phase of an aqueous solution of MEA at high $\mathrm{CO}_{2}$ loading $\left(\alpha_{\mathrm{CO}_{2}}=0.894 \mathrm{~mol} / \mathrm{mol}\right)$ and moderate temperature $(T=293 \mathrm{~K})$. By employing two-dimensional NMR techniques, all peaks were assigned to species and the molecular structure of all species was elucidated. Details on the two-dimensional NMR studies are presented in the Supplementary Material. An overview of the species found in the solution including the notation of their groups is given in Figure 2. For brevity, the carbamate of MEA is abbreviated as $\mathrm{MEA}_{1}$, the monoalkylcarbonate of MEA is abbreviated as $\mathrm{MEA}_{2}$, and the monoalkylcarbonate of the carbamate of MEA is abbreviated as $\mathrm{MEA}_{3}$. 
The following reactions $(\mathrm{I})-(\mathrm{V})$ are commonly considered to describe the chemical equilibrium in the system $\mathrm{MEA}-\mathrm{H}_{2} \mathrm{O}-\mathrm{CO}_{2}[9]$ :

$$
\begin{aligned}
\mathrm{H}_{2} \mathrm{O} & \rightleftharpoons \mathrm{H}^{+}+\mathrm{OH}^{-} \\
\mathrm{CO}_{2}+\mathrm{H}_{2} \mathrm{O} & \rightleftharpoons \mathrm{HCO}_{3}{ }^{-}+\mathrm{H}^{+} \\
\mathrm{HCO}_{3}{ }^{-} & \rightleftharpoons \mathrm{CO}_{3}{ }^{2-}+\mathrm{H}^{+} \\
\mathrm{MEAH}^{+} & \rightleftharpoons \mathrm{MEA}^{+} \mathrm{H}^{+} \\
\mathrm{MEA}+\mathrm{HCO}_{3}^{-} & \rightleftharpoons \mathrm{MEA}_{1}+\mathrm{H}_{2} \mathrm{O}
\end{aligned}
$$

The formation of the monoalkylcarbonates $\mathrm{MEA}_{2}$ and $\mathrm{MEA}_{3}$ is described here by additional reactions (VI)-(VII

$$
\begin{array}{r}
\mathrm{MEAH}^{+}+\mathrm{HCO}_{3}{ }^{-} \rightleftharpoons \mathrm{MEA}_{2}+\mathrm{H}_{2} \mathrm{O} \\
\mathrm{MEA}_{1}+\mathrm{HCO}_{3}{ }^{-} \rightleftharpoons \mathrm{MEA}_{3}+\mathrm{H}_{2} \mathrm{O}
\end{array}
$$

Reactions $(\mathrm{VI})$ and $(\mathrm{VII})$ are analogous to those used in our previous work on the formation of the monoalkylcarbonates of MDEA [1]. In principle, not only $\mathrm{MEAH}^{+}$but also the unprotonated MEA should be able to form monoalkylcarbonates. However, at low $\mathrm{CO}_{2}$ loadings where only MEA is present in the solution, we found no monoalkylcarbonates. We assume, that at low $\mathrm{CO}_{2}$ loadings the formation of monoalkylcarbonates from MEA is prevented by the much stronger formation of carbamates. Therefore, the formation of monoalkylcarbonates of the unprotonated MEA is neglected here. 


\section{Experimental}

\subsection{Chemicals}

Table 1 gives information on the used chemicals, the suppliers and the purities. All chemicals were used without further purification. Water was deionized and purified with a water purification system (Milli-Q Reference A + System, Merck Millipore).

Table 1: Provenance and purity of the pure components.

\begin{tabular}{llllll}
\hline chemical name & source & initial fraction purity & purification method & final fraction purity & analysis method \\
\hline $\mathrm{MEA}^{\mathrm{a}}$ & Sigma-Aldrich & $\geq 0.99 \mathrm{~g} / \mathrm{g}$ & none & $\geq 0.99 \mathrm{~g} / \mathrm{g}$ & stated by supplier \\
$\mathrm{OXA}^{\mathrm{b}}$ & Sigma-Aldrich & $\geq 0.998 \mathrm{~g} / \mathrm{g}$ & none & $\geq 0.998 \mathrm{~g} / \mathrm{g}$ & stated by supplier \\
$\mathrm{D}_{2} \mathrm{O}^{\mathrm{c}}$ & Sigma-Aldrich & $\geq 0.999 \mathrm{~mol} / \mathrm{mol}$ & none & $\geq 0.999 \mathrm{~mol} / \mathrm{mol}$ & stated by supplier \\
$\mathrm{CO}_{2}$ & Air Liquide & $\geq 0.99995 \mathrm{~mol} / \mathrm{mol}$ & none & $\geq 0.99995 \mathrm{~mol} / \mathrm{mol}$ & stated by supplier \\
methanol & Merck & $\geq 0.998 \mathrm{~g} / \mathrm{g}$ & none & $\geq 0.998 \mathrm{~g} / \mathrm{g}$ & stated by supplier \\
$\mathrm{H}_{2} \mathrm{O}$ & SWK & ion-exchange and filtration & $>0.99999 \mathrm{~g} / \mathrm{g}$ & conductometry \\
\hline${ }^{\mathrm{a}} \mathrm{MEA}=$ monoethanolamine (IUPAC: 2-aminoethanol) & & & \\
${ }^{\mathrm{b}} \mathrm{OXA}=$ oxazolidone (IUPAC: 1,3-oxazolidin-2-one & & & \\
${ }^{\mathrm{c}} \mathrm{D}_{2} \mathrm{O}=$ deuterium oxide & & & \\
${ }^{\mathrm{d}}$ Stadtwerke Kaiserslautern & & &
\end{tabular}

\subsection{Experimental Procedure}

In this work, two different procedures were used to prepare samples of MEA- $\mathrm{H}_{2} \mathrm{O}-\mathrm{CO}_{2}$. In the first procedure, an aqueous solution of MEA was prepared gravimetrically using a laboratory balance (PR2003 Comparator, Mettler Toledo, estimated standard uncertainty of the mass fraction of MEA: $\left.u\left(w_{\text {MEA }}^{0}\right)=0.00002 \mathrm{~g} / \mathrm{g}\right)$, and then loaded inside a valved NMR sample tube with $\mathrm{CO}_{2}$ at room temperature. Details on this procedure are described in the previous work of our group [1].

The second procedure was first developed in our group to prepare samples for the investigation of the solubility of $\mathrm{CO}_{2}$ in aqueous solution of amines [10]. This procedure was used here to prepare large quantities of $\mathrm{CO}_{2}$ 
loaded aqueous solution of MEA that were not only used for the studies presented in this paper but also for the determination of other physico-chemical properties. An aqueous solution of MEA was prepared under vacuum in a glass cylinder. The composition was determined gravimetrically with the same laboratory balance and the same standard uncertainty as mentioned above. The aqueous solution of MEA was then transferred into an evacuated pressure resistant stainless steel container, and charged with $\mathrm{CO}_{2}$. To attain equilibirium, the container was rotated for about $4-5 \mathrm{~h}$ and finally stored for about $24 \mathrm{~h}$. The container with the equilibrated $\mathrm{CO}_{2}$ loaded aqueous solution of MEA was then connected to a valved NMR sample tube which was pressurized with nitrogen at 1.2 bar. The container was then pressurized with nitrogen and the $\mathrm{CO}_{2}$ loaded aqueous solution of MEA was transferred through a riser in the container into the valved NMR sample tube. The pressurization of the sample tube prevented flashing of the solution during the filling process. More details on the second procedure is given in the Supplementary Material.

After a valved NMR sample tube filled with a $\mathrm{CO}_{2}$ loaded aqueous solution of MEA had been prepared, it was placed in an oven and was equilibrated for 4 hours at a certain temperature (estimated standard uncertainty of the temperature $T: u(T)=1 \mathrm{~K})$. Then, the NMR sample tube was placed inside the NMR spectrometer. The temperature of the sample tube was controlled using the nitrogen gas flow provided by the NMR spectrometer. The temperature inside the sample was determined from the reading of the temperature control of the NMR spectrometer using a calibration curve that was determined in calibration experiments with methanol as described by Ammann 
et al. [11]. The estimated standard uncertainty of the temperature of the sample is $u(T)=0.5 \mathrm{~K}$.

\subsection{NMR Spectroscopy and Data Analysis}

Like in our previous study [1], the composition of the liquid phase was determined with quantitative ${ }^{13} \mathrm{C}$ NMR spectroscopy. The NMR settings and the evaluation are presented here again as certain changes were made for the system MEA- $\mathrm{H}_{2} \mathrm{O}-\mathrm{CO}_{2}$. In this work, two $400 \mathrm{MHz}$ NMR spectrometer of Bruker (magnet: Ascend 400, console: Avance 3 HD 400) were used. Each NMR spectrometer was equipped with a probe, both from Bruker: one with cryogenically cooled electronics (Probe 1: CyroProbe Prodigy), the other with standard electronics (Probe 2: Double Resonance Broad Band Probe).

All quantitative measurements were carried out with a ${ }^{13} \mathrm{C}$ inverse gated pulse sequence: $30^{\circ}, 60^{\circ}$, or $90^{\circ}$ flip angle, 60 s relaxation delay, and 64-2048 scans based on experience from previous work on similar systems [1]. For a $90^{\circ}$ flip angle, the pulse repetition time should be $5 \times T_{1}$ to ensure quantitative measurements [12]. The carbon atom of the carbamate group of $\mathrm{MEA}_{1}$ has the longest $T_{1}$-relaxation time $\left(T_{1}=6 \mathrm{~s}\right)$ such that this requirement is easily fulfilled. The post-processing was carried out manually. The peak areas, $A_{i}$, were determined by direct integration. The full set of acquisition and processing parameters are listed in the Supplementary Material.

The results were expressed as molar ratios, $\zeta_{i}$, of the amount of species $i$, $n_{i}$, related to the sum of the amount of all carbon-containing species: 


$$
\zeta_{i}=\frac{n_{i}}{\sum_{i=1}^{N_{\mathrm{C}}} n_{i}}
$$

where $N_{\mathrm{C}}$ is the number of all carbon-containig species. Furthermore, from the evaluation of the ${ }^{13} \mathrm{C}$ NMR spectra information on the $\mathrm{CO}_{2}$ loading of the aqueous solution of MEA was obtained. The $\mathrm{CO}_{2}$ loading, $\alpha_{\mathrm{CO}_{2}}$, was defined as the overall amount of absorbed $\mathrm{CO}_{2}, \widetilde{n}_{\mathrm{CO}_{2}}$, related to the overall amount of MEA, $\widetilde{n}_{\mathrm{MEA}}$, in the liquid phase:

$$
\alpha_{\mathrm{CO}_{2}}=\frac{\widetilde{n}_{\mathrm{CO}_{2}}}{\widetilde{n}_{\mathrm{MEA}}}
$$

According to the Reactions (I)-(VII), $\alpha_{\mathrm{CO}_{2}}$ was calculated from the true amounts of substance as follows:

$$
\alpha_{\mathrm{CO}_{2}}=\frac{n_{\mathrm{CO}_{2}}+n_{\mathrm{HCO}_{3}^{-}}+n_{\mathrm{CO}_{3}^{2-}}+n_{\mathrm{MEA}_{1}}+n_{\mathrm{MEA}_{2}}+2 \cdot n_{\mathrm{MEA}_{3}}}{n_{\mathrm{MEA}}+n_{\mathrm{MEAH}^{+}}+n_{\mathrm{MEA}_{1}}+n_{\mathrm{MEA}_{2}}+n_{\mathrm{MEA}_{3}}}
$$

The molar ratio, $\zeta_{i}$, and the $\mathrm{CO}_{2}$ loading, $\alpha_{\mathrm{CO}_{2}}$, were determined directly from the areas, $A_{i}$, under the peaks that correspond to the species $i$ as described below. Figure 1 shows an example for a ${ }^{13} \mathrm{C}$ NMR spectrum of an aqueous solution of MEA at high $\mathrm{CO}_{2}$ loading $\left(\alpha_{\mathrm{CO}_{2}}=0.894 \mathrm{~mol} / \mathrm{mol}\right)$ and moderate temperature $(T=293 \mathrm{~K})$. By employing two-dimensional NMR techniques, the peaks were assigned to the different species. Details 
on the two-dimensional NMR techniques are presented in the Supplementary Material. The notation scheme of the groups of the MEA species is depicted in Figure 2, A two-digit notation scheme is used here. The first digit indicates the position and type of the group within a molecule. The second digit represents the species: 0 for $\mathrm{MEA}$ and $\mathrm{MEAH}^{+}, 1$ for $\mathrm{MEA}_{1}, 2$ for $\mathrm{MEA}_{2}$, and 3 for $\mathrm{MEA}_{3}$. Protonated and unprotonated species cannot be distinguished in the NMR spectra. Like in our previous work [1], an index " $\mathrm{x}$ " is used, which represents the number of fast exchanging protons per molecule. In this work, only peaks were evaluated that do not overlap with other peaks.

Because of the chosen NMR sequence, the peak areas, $A_{i}$, are directly proportional to the number of nuclei that cause the peak. Furthermore, it is shown that the proportionality factors are the same for all carbon nuclei [1]. Therefore, the observed values, $\zeta_{i}^{\text {obs }}$ and $\alpha_{\mathrm{CO}_{2}}^{\text {obs }}$, were obtained directly from the peak areas:

$$
\begin{aligned}
\zeta_{i}^{\mathrm{obs}} & =\frac{A_{i}}{\sum_{i=1}^{N_{\mathrm{C}}} A_{i}} \\
\alpha_{\mathrm{CO}_{2}}^{\mathrm{obs}} & =\frac{A_{\mathrm{CO}_{2}}+A_{\mathrm{H}_{\mathrm{x}} \mathrm{CO}_{3}}+A_{\mathrm{MEA}_{1}}+A_{\mathrm{MEA}_{2}}+2 \cdot A_{\mathrm{MEA}_{3}}}{A_{\mathrm{MEAH}_{\mathrm{x}}}+A_{\mathrm{MEA}_{1}}+A_{\mathrm{MEA}_{2}}+A_{\mathrm{MEA}_{3}}}
\end{aligned}
$$

When more than one non-overlapping peak of a species was evaluable, the mean of the corresponding peak areas was used.

Mole fractions, $x_{i}^{\text {obs }}$, were calculated from: 


$$
x_{i}^{\mathrm{obs}}=\frac{A_{i}}{\left(A_{\mathrm{MEAH}_{\mathrm{x}}}+A_{\mathrm{MEA}_{1}}+A_{\mathrm{MEA}_{2}}+A_{\mathrm{MEA}_{3}}\right)\left(X_{\mathrm{H}_{2} \mathrm{O}, \mathrm{MEA}}^{(\mathrm{n}, 0, \mathrm{obs}}+1\right)+A_{\mathrm{CO}_{2}}}
$$

where $X_{\mathrm{H}_{2} \mathrm{O}, \text { MEA }}^{(\mathrm{n}), 0 \text { obs }}$ is the molar loading of MEA with water in the unloaded stock solution which is available from the gravimetric preparation of the samples.

The relative standard uncertainty of the $\mathrm{CO}_{2}$ loading is estimated to be about $u_{\mathrm{r}}\left(\alpha_{\mathrm{CO}_{2}}\right)=0.05$ with a minimal standard uncertainty of $u\left(\alpha_{\mathrm{CO}_{2}}\right)=$ $0.03 \mathrm{~mol} / \mathrm{mol}$. The relative standard uncertainty of the mole fractions is estimated to be about $u_{\mathrm{r}}\left(x_{i}\right)=0.05$ except for mole fractions below $0.001 \mathrm{~mol} / \mathrm{mol}$ where it is about $u_{\mathrm{r}}\left(x_{i}\right)=0.1$. These numbers are adopted from our previous study on a similar system that was evaluated with the same methods and for which a detailed investigation of the uncertainty was carried out [1].

\section{Modeling and Parameter Estimation}

The chemical equilibrium of the reaction $j$ (with $j=$ I....VII) is described here in the same way like in the model of the previous work [1]. Molality based activities normalized similar to Henry's law for all solutes (including MEA) and a mole fraction based activity normalized according to Raoult's law for water were used: 


$$
\begin{aligned}
K_{\mathrm{a}, j}(T) & =\prod_{i}^{N} a_{i}^{\nu_{i, j}} \\
\text { with } a_{\mathrm{H}_{2} \mathrm{O}} & =x_{\mathrm{H}_{2} \mathrm{O}} \cdot \gamma_{\mathrm{H}_{2} \mathrm{O}} \\
\text { and } a_{i} & =\frac{m_{i}}{m^{0}} \gamma_{i}^{\mathrm{m} *} \text { for all } i \neq \mathrm{H}_{2} \mathrm{O} .
\end{aligned}
$$

$\nu_{i, j}$ is the stoichiometric factor of species $i$ for reaction $j$. The dependence of the chemical potential on pressure is neglected so that the chemical equilibrium constant, $K_{\mathrm{a}, j}$, is only a function of temperature. The temperature dependence of the chemical equilibrium constants is described by empirical correlations. For Reactions (I) $-(\mathrm{V})$ these correlations were taken from Wagner et al. [9]. The activity coefficients, $\gamma_{i}^{\mathrm{m} *}$, of all species but water are described using an extended form of Pitzer's equation [13, 14]. Where available, the interaction parameters were taken from Wagner et al. [9]. The parameters describing the interaction of the new species $\mathrm{MEA}_{2}$ and $\mathrm{MEA}_{3}$ with all other species were set to zero. Thus, the activity coefficients of these two species are described by the contribution from the Debye-Hückel-term (empirically modified by Pitzer [13, 14]) only. The activity coefficient, $\gamma_{\mathrm{H}_{2} \mathrm{O}}$, of water is calculated from the Gibbs-Duhem equation.

Using Eq. (7), the molar ratio, $\zeta_{i}^{\text {model }}$, was calculated as a function of

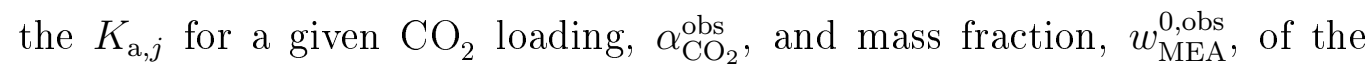
aqueous stock solution of MEA. The chemical equilibrium constants for Reactions $(\mathrm{VI})$ and $(\mathrm{VII})$ were determined by solving the minimization problem using the sum of squared errors as objective function: 


$$
\begin{aligned}
K_{\mathrm{a}, j}\left(T_{l}\right) & =\underset{K_{\mathrm{a}, j} \in \mathbb{R}^{+}}{\arg \min } \sum_{k=1}^{M_{l}} \sum_{i=1}^{2}\left(\zeta_{i, k}^{\mathrm{obs}}-\zeta_{i}^{\text {model }}\left(K_{\mathrm{a}, j}\left(T_{l}\right), \alpha_{\mathrm{CO}_{2}, k}^{\mathrm{obs}}, w_{\mathrm{MEA}, k}^{0, \mathrm{obs}}\right)\right)^{2} \\
i & =\left\{1 \text { for } \mathrm{MEA}_{2}, 2 \text { for } \mathrm{MEA}_{3}\right\} \\
k & =1 \ldots M_{l}
\end{aligned}
$$

where $M_{l}$ is the total number of observations carried out at the temperature $T_{l}$. The optimization problem was solved in MATLAB using a trust-region algorithm embedded in the MATLAB solver lsqnonlin. $\zeta_{i}^{\text {model }}$ was calculated using a Newton-Raphson algorithm.

\section{Results and Discussion}

\subsection{Experimental}

In ${ }^{13} \mathrm{C}$ NMR spectra of the system $\mathrm{MEA}-\mathrm{H}_{2} \mathrm{O}-\mathrm{CO}_{2}$, the NMR peaks of the monoalkylcarbonate of MEA $\left(\mathrm{MEA}_{2}\right)$ can be easily misinterpreted as oxazolidone because of similar ${ }^{13} \mathrm{C}$ NMR shifts. As a consequence, Böttinger et al. [6] reported ${ }^{13} \mathrm{C}$ NMR peaks as oxazolidone. In the present work, however, these peaks were unambiguously assigned to $\mathrm{MEA}_{2}$. We proofed that $\mathrm{MEA}_{2}$ is formed instead of oxazolidone by comparing the ${ }^{1} \mathrm{H}_{-}{ }^{13} \mathrm{C}$ Heteronuclear Multiple Bond Correlation (HMBC) NMR spectrum of a $\mathrm{CO}_{2}$ loaded aqueous solution of MEA with the HMBC NMR spectrum of oxazolidone dissolved in $\mathrm{D}_{2} \mathrm{O}$. In HMBC NMR spectra, multiple bond ${ }^{1} \mathrm{H}-{ }^{13} \mathrm{C}$ correlations are observed allowing the assignment of protons with a two to three bonds distance from a carbon atom. Because of the different chemical structure of the linear $\mathrm{MEA}_{2}$ and the circular oxazolidone, the carbon atom of the car- 
bonate group of $\mathrm{MEA}_{2}$ only correlates with the protons of one $\mathrm{CH}_{2}$ group, whereas the carbon atom of the carbonyl group of oxazolidone correlates with both $\mathrm{CH}_{2}$ groups. The HMBC NMR spectra and more details on the structure elucidation of all species are given in the Supplementary Material.

The composition of aqueous solutions containing $0.3 \mathrm{~g} / \mathrm{g}$ of MEA at $293 \mathrm{~K}$ is presented in Figure 3 as a function of the $\mathrm{CO}_{2}$ loading. Both the experimental data of this work and of Böttinger et al. [6] are plotted. The results from the model developed in the present work are shown as well. The corresponding numerical values are listed in Table 2. The numerical values of the molar ratio, $\zeta_{i}$, are listed in Table S2 in the Supplementary Material.

The data of this work agree well with the data of Böttinger et al. [6], which were obtained also by NMR spectroscopy, but with a significantly different method. Only at $\mathrm{CO}_{2}$ loadings above $0.8 \mathrm{~mol} / \mathrm{mol}$ minor deviations are observed for the experimental results of $\mathrm{MEAH}_{\mathrm{x}}$. Consistent with the finding that oxazoldione was a misinterpretation of $\mathrm{MEA}_{2}$, the mole fractions of oxazolidone published by Böttinger et al. [6] are in good agreement with the mole fractions of the $\mathrm{MEA}_{2}$ measured in the present work. Because of the technical advances in NMR spectroscopy, the limit of quantification of the NMR spectrometer used in the present work is lower than the limit of quantification of the NMR spectrometer of Böttinger et al. [6]. For this reason, no experimental data of Böttinger et al. [6] are available for $\mathrm{MEA}_{3}$. Furthermore, molecular $\mathrm{CO}_{2}$ could be quantified in the present work also for $\mathrm{CO}_{2}$ loadings at which Böttinger et al. [6] could not get such data.

The experimental results (cf. Figure 3) show that at $\mathrm{CO}_{2}$ loadings below $0.5 \mathrm{~mol} / \mathrm{mol}$ the absorbed $\mathrm{CO}_{2}$ is completely bound in $\mathrm{MEA}_{1}$. At $\mathrm{CO}_{2}$ 
Table 2: Experimental values of mole fraction $x_{i}$ at temperature $T$, mass fraction $w_{\mathrm{MEA}}^{0}$ of MEA in the unloaded aqueous stock solution, and $\mathrm{CO}_{2}$ loading $\alpha_{\mathrm{CO}_{2}}$ with standard uncertainty $u\left(\alpha_{\mathrm{CO}_{2}}\right)$ for the liquid phase of the system MEA- $\mathrm{H}_{2} \mathrm{O}-\mathrm{CO}_{2}$ in chemical equilibrium. ${ }^{\text {a }}$

\begin{tabular}{|c|c|c|c|c|c|c|c|c|c|}
\hline $\begin{array}{l}T \\
\mathrm{~K}\end{array}$ & $\begin{array}{l}w_{\mathrm{MEA}}^{0} \\
\mathrm{~g} / \mathrm{g}\end{array}$ & $\begin{array}{l}\alpha_{\mathrm{CO}_{2}} \\
\mathrm{~mol} / \mathrm{mol}\end{array}$ & $\begin{array}{l}u\left(\alpha_{\mathrm{CO}_{2}}\right) \\
\mathrm{mol} / \mathrm{mol}\end{array}$ & $\begin{array}{l}x_{\mathrm{CO} 2} \\
\mathrm{~mol} / \mathrm{mol}\end{array}$ & $\begin{array}{l}x_{\mathrm{H}_{\mathrm{x}} \mathrm{CO} 3} \\
\mathrm{~mol} / \mathrm{mol}\end{array}$ & $\begin{array}{l}x_{\mathrm{MEAH}_{\mathrm{x}}} \\
\mathrm{mol} / \mathrm{mol}\end{array}$ & $\begin{array}{l}x_{\mathrm{MEA}_{1}} \\
\mathrm{~mol} / \mathrm{mol}\end{array}$ & $\begin{array}{l}x_{\mathrm{MEA}_{2}} \\
\mathrm{~mol} / \mathrm{mol}\end{array}$ & $\begin{array}{l}x_{\mathrm{MEA}_{3}} \\
\mathrm{~mol} / \mathrm{mol}\end{array}$ \\
\hline \multirow[t]{29}{*}{293.15} & \multirow[t]{3}{*}{0.150} & 0.24 & 0.03 & - & - & 0.0377 & 0.0117 & - & - \\
\hline & & 0.48 & 0.03 & - & 0.0030 & 0.0286 & 0.0208 & - & - \\
\hline & & 0.50 & 0.03 & - & 0.0036 & 0.0285 & 0.0210 & - & - \\
\hline & \multirow[t]{3}{*}{0.146} & 0.50 & 0.03 & - & 0.0036 & 0.0278 & 0.0203 & - & - \\
\hline & & 0.50 & 0.03 & - & 0.0036 & 0.0277 & 0.0204 & - & - \\
\hline & & 0.52 & 0.03 & - & 0.0041 & 0.0274 & 0.0206 & - & - \\
\hline & \multirow[t]{2}{*}{0.153} & 0.65 & 0.03 & - & 0.0168 & 0.0346 & 0.0153 & 0.0002 & 0.0003 \\
\hline & & 0.66 & 0.03 & - & 0.0167 & 0.0342 & 0.0156 & 0.0002 & 0.0004 \\
\hline & \multirow[t]{3}{*}{0.150} & 0.69 & 0.03 & - & 0.0185 & 0.0342 & 0.0145 & 0.0005 & 0.0003 \\
\hline & & 0.69 & 0.03 & - & 0.0186 & 0.0342 & 0.0146 & 0.0004 & 0.0003 \\
\hline & & 0.99 & 0.05 & 0.0024 & 0.0409 & 0.0442 & 0.0038 & 0.0013 & 0.0001 \\
\hline & 0.300 & 0.06 & 0.03 & - & - & 0.1060 & 0.0062 & - & - \\
\hline & \multirow[t]{3}{*}{0.301} & 0.08 & 0.03 & - & - & 0.1037 & 0.0089 & - & - \\
\hline & & 0.11 & 0.03 & - & - & 0.1005 & 0.0121 & - & - \\
\hline & & 0.11 & 0.03 & - & - & 0.1005 & 0.0122 & - & - \\
\hline & 0.300 & 0.26 & 0.03 & - & 0.0008 & 0.0833 & 0.0288 & - & - \\
\hline & \multirow{3}{*}{0.301} & 0.32 & 0.03 & - & - & 0.0767 & 0.0359 & - & - \\
\hline & & 0.32 & 0.03 & - & - & 0.0763 & 0.0363 & - & - \\
\hline & & 0.33 & 0.03 & - & 0.0013 & 0.0766 & 0.0360 & - & - \\
\hline & \multirow[t]{2}{*}{0.300} & 0.45 & 0.03 & - & 0.0031 & 0.0649 & 0.0474 & - & - \\
\hline & & 0.56 & 0.03 & - & 0.0151 & 0.0655 & 0.0454 & 0.0006 & 0.0007 \\
\hline & \multirow[t]{3}{*}{0.301} & 0.60 & 0.03 & - & 0.0250 & 0.0710 & 0.0396 & 0.0011 & 0.0010 \\
\hline & & 0.60 & 0.03 & - & 0.0248 & 0.0705 & 0.0398 & 0.0011 & 0.0012 \\
\hline & & 0.62 & 0.03 & - & 0.0252 & 0.0691 & 0.0412 & 0.0012 & 0.0011 \\
\hline & \multirow[t]{5}{*}{0.300} & 0.64 & 0.03 & - & 0.0324 & 0.0743 & 0.0352 & 0.0016 & 0.0012 \\
\hline & & 0.70 & 0.03 & - & 0.0424 & 0.0776 & 0.0314 & 0.0019 & 0.0012 \\
\hline & & 0.83 & 0.04 & 0.0014 & 0.0644 & 0.0863 & 0.0204 & 0.0036 & 0.0015 \\
\hline & & 0.88 & 0.04 & 0.0021 & 0.0727 & 0.0900 & 0.0166 & 0.0040 & 0.0012 \\
\hline & & 0.89 & 0.04 & 0.0029 & 0.0756 & 0.0917 & 0.0144 & 0.0044 & 0.0013 \\
\hline \multirow[t]{9}{*}{298.15} & \multirow[t]{3}{*}{0.150} & 0.69 & 0.03 & - & 0.0190 & 0.0346 & 0.0141 & 0.0005 & 0.0002 \\
\hline & & 0.74 & 0.04 & - & 0.0235 & 0.0365 & 0.0119 & 0.0007 & 0.0003 \\
\hline & & 0.90 & 0.05 & 0.0012 & 0.0355 & 0.0416 & 0.0065 & 0.0011 & 0.0002 \\
\hline & \multirow[t]{6}{*}{0.300} & 0.17 & 0.03 & - & 0.0006 & 0.0933 & 0.0188 & - & - \\
\hline & & 0.26 & 0.03 & - & 0.0007 & 0.0832 & 0.0289 & - & - \\
\hline & & 0.31 & 0.03 & - & 0.0010 & 0.0780 & 0.0340 & - & - \\
\hline & & 0.45 & 0.03 & - & 0.0028 & 0.0644 & 0.0475 & - & 0.0001 \\
\hline & & 0.51 & 0.03 & - & 0.0067 & 0.0617 & 0.0498 & 0.0002 & 0.0003 \\
\hline & & 0.69 & 0.03 & - & 0.0392 & 0.0758 & 0.0328 & 0.0019 & 0.0015 \\
\hline \multirow[t]{10}{*}{313.15} & \multirow[t]{3}{*}{0.150} & 0.66 & 0.03 & - & 0.0188 & 0.0355 & 0.0137 & 0.0003 & - \\
\hline & & 0.83 & 0.04 & - & 0.0327 & 0.0412 & 0.0072 & 0.0011 & - \\
\hline & & 0.90 & 0.05 & 0.0033 & 0.0352 & 0.0433 & 0.0047 & 0.0012 & - \\
\hline & 0.311 & 0.30 & 0.03 & - & - & 0.0823 & 0.0354 & - & - \\
\hline & 0.300 & 0.44 & 0.03 & - & 0.0025 & 0.0652 & 0.0469 & - & - \\
\hline & 0.275 & 0.49 & 0.03 & - & 0.0047 & 0.0564 & 0.0443 & - & - \\
\hline & 0.311 & 0.53 & 0.03 & - & 0.0126 & 0.0683 & 0.0494 & - & - \\
\hline & 0.275 & 0.68 & 0.03 & - & 0.0355 & 0.0684 & 0.0295 & 0.0018 & 0.0011 \\
\hline & \multirow[t]{2}{*}{0.300} & 0.69 & 0.03 & - & 0.0381 & 0.0747 & 0.0343 & 0.0018 & 0.0014 \\
\hline & & 0.70 & 0.03 & - & 0.0444 & 0.0789 & 0.0305 & 0.0018 & 0.0008 \\
\hline
\end{tabular}

a Standard uncertainties: $u(T)=0.5 \mathrm{~K}, u\left(w_{\text {MEA }}^{0}\right)=0.00002 \mathrm{~g} / \mathrm{g}$. Relative standard uncertainties: $u_{\mathrm{r}}\left(x_{i}\right)=0.1$ for $x_{i}<0.001 \mathrm{~mol} / \mathrm{mol}, u_{\mathrm{r}}\left(x_{i}\right)=0.05$ for $x_{i}>0.001 \mathrm{~mol} / \mathrm{mol}$. 
loadings above $0.5 \mathrm{~mol} / \mathrm{mol} \mathrm{CO}_{2}$ is also bound in $\mathrm{H}_{\mathrm{x}} \mathrm{CO}_{3}$ (bicarbonate and carbonate) and the amount of $\mathrm{MEA}_{1}$ decreases with increasing $\mathrm{CO}_{2}$ loading. At the same time, $\mathrm{MEA}_{2}$ and $\mathrm{MEA}_{3}$ are formed. The amount of $\mathrm{MEA}_{2}$ continuously increases with increasing $\mathrm{CO}_{2}$ loading while the amount of $\mathrm{MEA}_{3}$ reaches a maximum at a $\mathrm{CO}_{2}$ loading of about $0.8 \mathrm{~mol} / \mathrm{mol}$.

\subsection{Chemical Equilibrium Constants of the Monoalkylcarbonate Formation}

The chemical equilibrium constants for the Reactions (VI) and (VII), which were determined by solving the minimization problem given in Eq. (8) for the different data sets, are listed in Table 3. The standard uncertainties $u\left(K_{\mathrm{a}, j}\right)$ reported in Table 3 are the $95 \%$ confidence intervals obtained from the parameter estimation procedure. The chemical equilibrium constants for the formation of $\mathrm{MEA}_{2}$ (Reaction (VI) ) are similar to the chemical equilibrium constants for the formation of the monoalkylcarbonate of $\mathrm{MDEAH}^{+}$[1]. It can be concluded that the reactivity of the hydroxyethyl group in forming alkylcarbonates is not significantly affected by the substitutes of the nitrogen atom.

Table 3: Chemical equilibrium constants $K_{\mathrm{a}, j}$ (on the molality scale) of the formation of $\mathrm{MEA}_{2}$ (Reaction (VI) and of $\mathrm{MEA}_{3}$ (Reaction (VII) with standard uncertainties $u\left(K_{\mathrm{a}, j}\right)$ at temperature $T .^{\mathrm{a}}$

\begin{tabular}{|c|c|c|c|c|}
\hline$T / \mathrm{K}$ & $1000 \cdot K_{\mathrm{a}, \mathrm{VI}}$ & $1000 \cdot u\left(K_{\mathrm{a}, \mathrm{VI}}\right)$ & $1000 \cdot K_{\mathrm{a}, \mathrm{VII}}$ & $1000 \cdot u\left(K_{\mathrm{a}, \mathrm{VII}}\right)$ \\
\hline 293.15 & 70.6 & 4.1 & 1.15 & 0.14 \\
\hline 298.15 & 70.4 & 5.0 & 1.26 & 0.18 \\
\hline 313.15 & 68.9 & 9.9 & 0.73 & 0.24 \\
\hline average & 70.0 & & 1.05 & \\
\hline
\end{tabular}

The chemical equilibirium constants in Table 3 show no significant tem- 
perature dependence. Also for the formation of the monoalkylcarbonates of MDEA no temperature dependence of the chemical equilibrium constants was observed [1].

\subsection{Simulation Results}

The upper bound of the range of the $\mathrm{CO}_{2}$ loading that is relevant for typical applications of aqueous MEA solutions in industrial gas absorption processes is $\alpha_{\mathrm{CO}_{2}}=0.5 \ldots 0.6 \mathrm{~mol} / \mathrm{mol}$ [15]. Up to this $\mathrm{CO}_{2}$ loading, the experimental results of all species are in very good agreement with the simulation results as depicted in Figure 3. Minor deviations between the experimental results and model prediction of $\mathrm{MEAH}_{\mathrm{x}}$ and of $\mathrm{MEA}_{1}$ are observed for $\mathrm{CO}_{2}$ loadings above $0.8 \mathrm{~mol} / \mathrm{mol}$. At those $\mathrm{CO}_{2}$ loadings, $\mathrm{MEA}_{2}, \mathrm{MEA}_{3}$ and $\mathrm{CO}_{2}$ are still well described. These results can be compared to those of the model of Wagner et al. [9], which does not account for the formation of $\mathrm{MEA}_{2}$ and $\mathrm{MEA}_{3}$. For the species that are accounted for in both models, the present model gives an improved description of the experimental data, as shown in the Supplementary Material.

The significance of the monoalkylcarbonates of MDEA was illustrated in the previous work by showing the distribution of the overall amount of absorbed $\mathrm{CO}_{2}$ to the different species [1]. This plot was also generated for the system studied here and is shown in Figure 4. It gives the results for an aqueous solution containing $0.3 \mathrm{~g} / \mathrm{g}$ of MEA at $293 \mathrm{~K}$ and can, hence, be compared directly to the corresponding plot for MDEA from our previous study [1]. In contrast to MDEA, where at all $\mathrm{CO}_{2}$ loadings about $10 \mathrm{~mol} \%$ $\mathrm{CO}_{2}$ is bound as monoalkylcarbonates, the amount of monoalkylcarbonates is negligible for MEA at $\mathrm{CO}_{2}$ loadings below $0.5 \mathrm{~mol} / \mathrm{mol}$. Only at $\mathrm{CO}_{2}$ 
loadings above $0.5 \mathrm{~mol} / \mathrm{mol}$ the combined amount of $\mathrm{CO}_{2}$ that is bound in $\mathrm{MEA}_{2}$ and $\mathrm{MEA}_{3}$ is about $10 \mathrm{~mol} \%$ and thus comparable to that observed in the system with MDEA.

In our previous work [1], the model of Ermatchkov and Maurer [16], which describes the vapor-liquid equilibrium of the system $\mathrm{MDEA}-\mathrm{H}_{2} \mathrm{O}-$ $\mathrm{CO}_{2}$, was extended to account for the presence of the monoalkylcarbonates. The extension of the model of Ermatchkov and Maurer [16] was found to be important regarding the composition of the liquid phase, but only minor regarding the overall gas solubility. The findings for the system that was studied in the present work are similar. The present model is an extension of the model of Wagner et al. [9] for describing the vapor-liquid equilibrium of the system MEA- $\mathrm{H}_{2} \mathrm{O}-\mathrm{CO}_{2}$. Figure 5 depicts the partial pressure of $\mathrm{CO}_{2}$, $p_{\mathrm{CO}_{2}}$, and the total pressure, $p$, as a function of the $\mathrm{CO}_{2}$ loading, $\alpha_{\mathrm{CO}_{2}}$, at $313 \mathrm{~K}$ for both models along with experimental data of Wagner et al. [9]. It can be seen that accounting for the monoalkylcarbonates in the model has only minor effect on the predicted partial pressure of $\mathrm{CO}_{2}, p_{\mathrm{CO}_{2}}$, and the total pressure,$p$. The reason for this is that neither the predicted activity of $\mathrm{CO}_{2}$ nor that of $\mathrm{H}_{2} \mathrm{O}$ is significantly changed by introducing the formation of the monoalkylcarbonates. Therefore, the extended Henry's law for $\mathrm{CO}_{2}$ and

the extended Raoult's law for $\mathrm{H}_{2} \mathrm{O}$ yield almost the same partial pressure of $\mathrm{CO}_{2}, p_{\mathrm{CO}_{2}}$, and the same total pressure, $p$.

\section{Conclusion}

In this work, the equilibrium composition of the liquid phase of the system $\mathrm{MEA}-\mathrm{H}_{2} \mathrm{O}-\mathrm{CO}_{2}$ was investigated. By using two-dimensional NMR spec- 
troscopy, it is proven that the monoalkylcarbonate of monoethanolamine (2ammonioethyl carbonate, abbreviated here as $\mathrm{MEA}_{2}$ ) and the monoalkylcarbonate of the carbamate of monoethanolamine (2-(carboxylatoamino)ethyl carbonate, abbreviated here as $\mathrm{MEA}_{3}$ ) are present in the liquid phase. At the same time, it is shown that no oxazolidone is present and that previous reports on that species result from a misinterpretation of signals from $\mathrm{MEA}_{2}$ [6]. Based on the new experimental data, a thermodynamic consistent model of the chemical equilibrium in the studied complex electrolyte solutions was developed. It is an extension of the model of Wagner et al. [9]. The extended model describes the composition in the complete $\mathrm{CO}_{2}$ loading range for the reported experimental conditions $(293-313 \mathrm{~K})$ very well.

The study shows that about $10 \mathrm{~mol} \%$ of the absorbed $\mathrm{CO}_{2}$ is bound in monoalkylcarbonates at $\mathrm{CO}_{2}$ loadings above $0.5 \mathrm{~mol} / \mathrm{mol}$. However, at $\mathrm{CO}_{2}$ loadings below $0.5 \mathrm{~mol} / \mathrm{mol}$ - i.e. the $\mathrm{CO}_{2}$ loading range relevant for technical applications - almost no $\mathrm{CO}_{2}$ is bound in monoalkylcarbonates. This finding can be explained by the concurrent formation of carbamates at $\mathrm{CO}_{2}$ loadings below $0.5 \mathrm{~mol} / \mathrm{mol}$.

However, monoalkylcarbonates could be important in the recovery and regeneration of MEA solutions. They could also play a role in the degradation of MEA. In the literature, oxazolinode has repeatedly been discussed as an intermediate in degradation routes [5, 7, 8]. It is shown here that $\mathrm{MEA}_{2}$ can be misinterpreted easily as oxazolidone, so that those degradation routes might have to be reevaluated. Based on the results from the present study, the amount of monoalkylcarbonates in mixtures of $\mathrm{MEA}$, water and $\mathrm{CO}_{2}$ can now be assessed. 


\section{Acknowledgements}

We thank Silvie Müller for her contributions to the experiments of the work.

\section{Funding}

This work was supported by the German Research Foundation (SFB/TRR 173 Spin + X).

\section{Appendix A. Supplementary Material}

Supplementary Material associated with this article can be found, in the online version, at ...

The Supplementary Material includes: Structure Elucidation by 2D NMR Spectroscopy, Experimental Procedure, NMR Acquisition and Processing Pa-

rameters, Simulation Results from the Model of Wagner et al., Numerical Results. 


\section{Nomenclature}

\section{Abbreviations}

$\mathrm{H}_{\mathrm{x}} \quad$ sum of a molecule with different amount of fast exchanging protons (e.g. $\mathrm{MEAH}_{\mathrm{x}}$ as the sum of MEA and $\mathrm{MEAH}^{+}$)

MDEA methyldiethanolamine

MEA monoethanolamine

$\mathrm{MEAH}^{+}$protonated form of monoethanolamine

$\mathrm{MEA}_{1} \quad$ carbamate of monoethanolamine

$\mathrm{MEA}_{2}$ monoalkylcarbonate of monoethanolamine

$\mathrm{MEA}_{3}$ monoalkylcarbonate of the carbamate of monoethanolamine

NMR nuclear magnetic resonance 
Symbols and Indices

\begin{tabular}{|c|c|}
\hline$A_{i}$ & peak area under a peak in a ${ }^{13} \mathrm{C}$ NMR spectrum \\
\hline & corresponding to the component $i$ \\
\hline$a_{i}$ & activity of component $i$ \\
\hline$K_{\mathrm{a}, j}$ & chemical equilibirium constant of reaction $j$ \\
\hline$m^{0}$ & reference molality: 1 mole solute per $1 \mathrm{~kg}$ of water \\
\hline$m_{i}$ & molality of component $i$ in pure water \\
\hline$M_{l}$ & total number of observations carried out at temperature $T_{l}$ \\
\hline$N$ & number of species \\
\hline$N_{C}$ & number of carbon-containing species \\
\hline$n_{i}$ & true amount of component $i$ \\
\hline$\tilde{n}_{i}$ & overall amount of component $i$ \\
\hline$T$ & temperature \\
\hline$w_{\mathrm{MEA}}^{0}$ & mass fraction of MEA in the unloaded aqueous stock solution \\
\hline$X_{\mathrm{H}_{2} \mathrm{O}, \mathrm{MEA}}^{(\mathrm{n}), 0}$ & molar loading of water in MEA in the unloaded aqueous stock solution \\
\hline$x_{i}$ & mole fraction of component $i$ \\
\hline$\alpha_{\mathrm{CO}_{2}}$ & $\mathrm{CO}_{2}$ loading \\
\hline$\gamma_{\mathrm{H}_{2} \mathrm{O}}$ & mole fraction based activity coefficient of water \\
\hline$\gamma_{i}^{\mathrm{m} *}$ & molality based activity coefficient of component $i$ \\
\hline$\delta^{13} \mathrm{C}$ & chemical shift of the ${ }^{13} \mathrm{C}$ NMR spectrum in ppm \\
\hline$\zeta_{i}$ & $\begin{array}{l}\text { molar ratio of component } i \text { related to the sum of the amount of all } \\
\text { carbon-containing species }\end{array}$ \\
\hline$\nu_{i, j}$ & stoichiometric factor of component $i$ for the reaction $j$ \\
\hline model & index for a calculated value \\
\hline bs & index for an observed value \\
\hline
\end{tabular}




\section{References}

[1] R. Behrens, E. von Harbou, W. R. Thiel, W. Böttinger, T. Ingram, G. Sieder, H. Hasse, Ind. Eng. Chem. Res. 56 (2017) 9006-9015. doi:10. 1021/acs.iecr.7b01937.

[2] H. Yamada, Y. Matsuzaki, K. Goto, Ind. Eng. Chem. Res. 53 (2014) 1617-1623. doi:10.1021/ie4034889.

[3] Z. Cieslarova, V. B. dos Santos, C. L. do Lago, International Journal of Greenhouse Gas Control 76 (2018) 142-149. doi:10.1016/j.ijggc. 2018.07 .005 .

[4] J. P. Jakobsen, J. Krane, H. F. Svendsen, Ind. Eng. Chem. Res. 44 (2005) 9894-9903. doi:10.1021/ie048813+.

[5] V. P. Talzi, S. V. Ignashin, Russian Journal of Applied Chemistry 75 (2002) 80-85. doi:10.1023/A:1015573008284.

[6] W. Böttinger, M. Maiwald, H. Hasse, Fluid Phase Equilibria 263 (2008) 131-143. doi:10.1016/j.fluid.2007.09.017.

[7] J. Davis, G. Rochelle, Energy Procedia 1 (2009) 327-333. doi:10.1016/ j.egypro.2009.01.045.

[8] A. F. Ciftja, A. Hartono, A. Grimstvedt, H. F. Svendsen, Energy Procedia 23 (2012) 111-118. doi:10.1016/j .egypro.2012.06.064.

[9] M. Wagner, I. von Harbou, J. Kim, I. Ermatchkova, G. Maurer, H. Hasse, J. Chem. Eng. Data 58 (2013) 883-895. doi:10.1021/ je301030z. 
[10] V. Ermatchkov, A. Pérez-Salado Kamps, G. Maurer, Ind. Eng. Chem. Res. 45 (2006) 6081-6091. doi:10.1021/ie0604270.

[11] C. Ammann, P. Meier, A. Merbach, Journal of Magnetic Resonance (1969) 46 (1982) 319-321. doi:10.1016/0022-2364(82) 90147-0.

[12] P. T. Callaghan, Principles of Nuclear Magnetic Resonance Microscopy, Clarendon Press, Oxford, 1993.

[13] K. S. Pitzer, J. Phys. Chem. 77 (1973) 268-277. doi:10.1021/ j100621a026.

[14] K. S. Pitzer, Activity Coefficients in Electrolyte Solutions, CRC Press, Boca Raton, FL, 1991.

[15] A. L. Kohl, R. Nielsen, Gas Purification, Gulf Pub., Houston, Tex., 1997.

[16] V. Ermatchkov, G. Maurer, Fluid Phase Equilibria 302 (2011) 338-346. doi:10.1016/j.fluid.2010.06.001. 


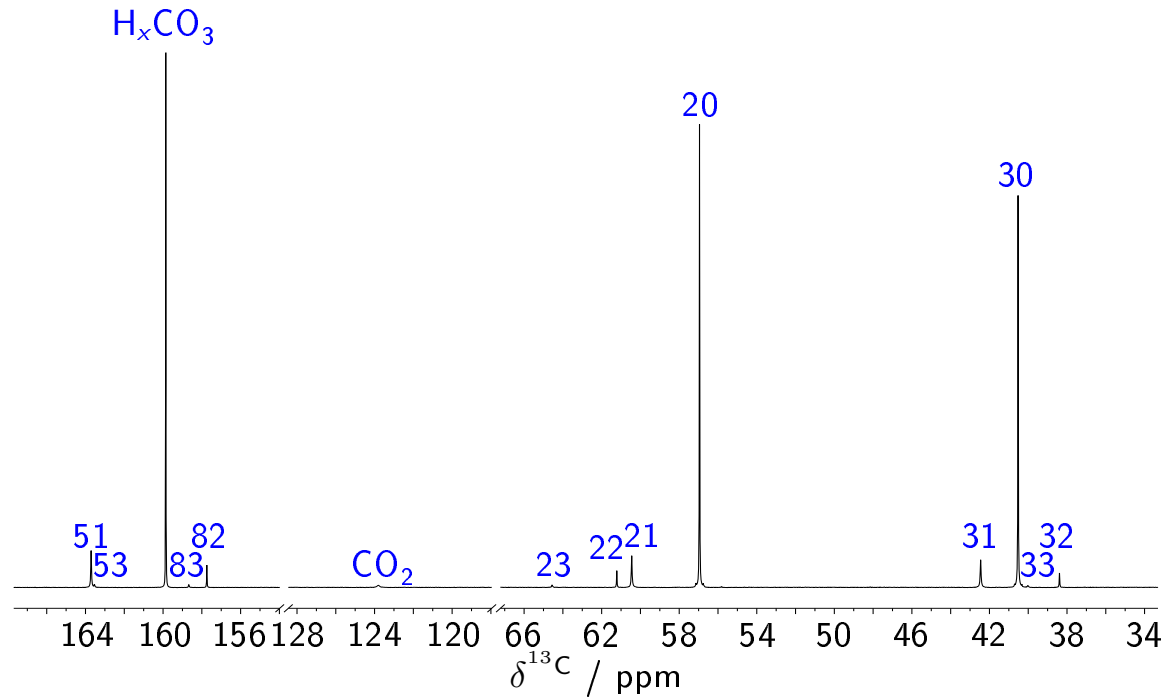

Figure 1: ${ }^{13} \mathrm{C}$ NMR spectrum of $\mathrm{MEA}-\mathrm{D}_{2} \mathrm{O}-\mathrm{CO}_{2}$, for $w_{\mathrm{MEA}}^{0}=0.3 \mathrm{~g} / \mathrm{g}$, $\alpha_{\mathrm{CO}_{2}}=0.894 \mathrm{~mol} / \mathrm{mol}, T=293 \mathrm{~K}$. Notation of the peaks according to Figure 2. The peak $\mathrm{H}_{\mathrm{x}} \mathrm{CO}_{3}$ results from $\mathrm{H}_{2} \mathrm{CO}_{3}, \mathrm{HCO}_{3}{ }^{-}$, and $\mathrm{CO}_{3}{ }^{2-}$. 

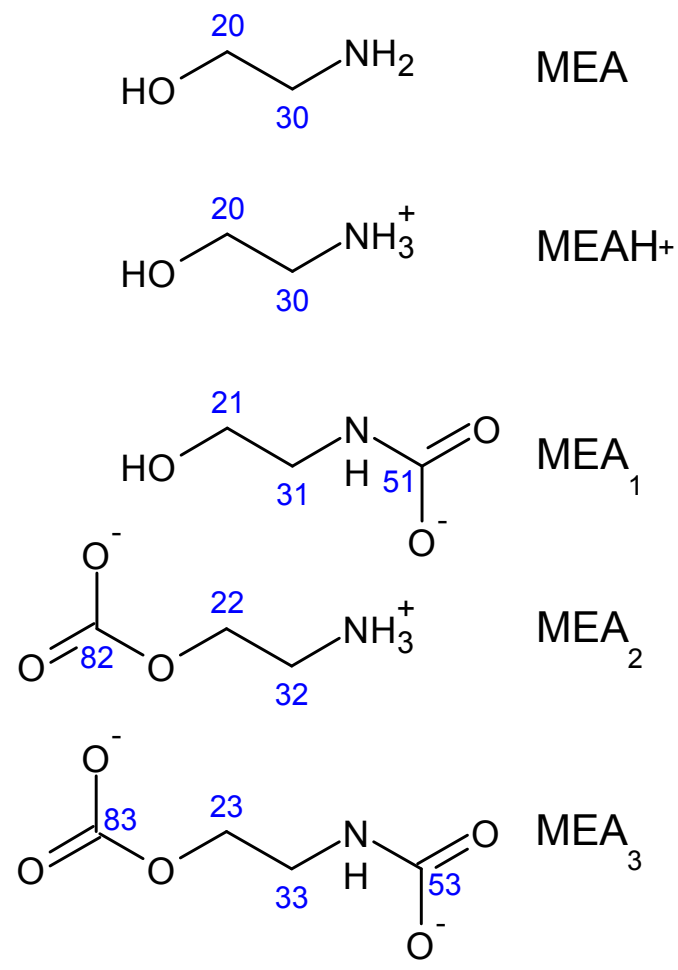

Figure 2: Chemical structure of MEA, MEAH ${ }^{+}$, carbamate of MEA $\left(\mathrm{MEA}_{1}\right), 2$ ammonioethyl carbonate $\left(\mathrm{MEA}_{2}\right)$, and 2-(carboxylatoamino)ethyl carbonate $\left(\mathrm{MEA}_{3}\right)$ with notation of the groups used in the present work. 

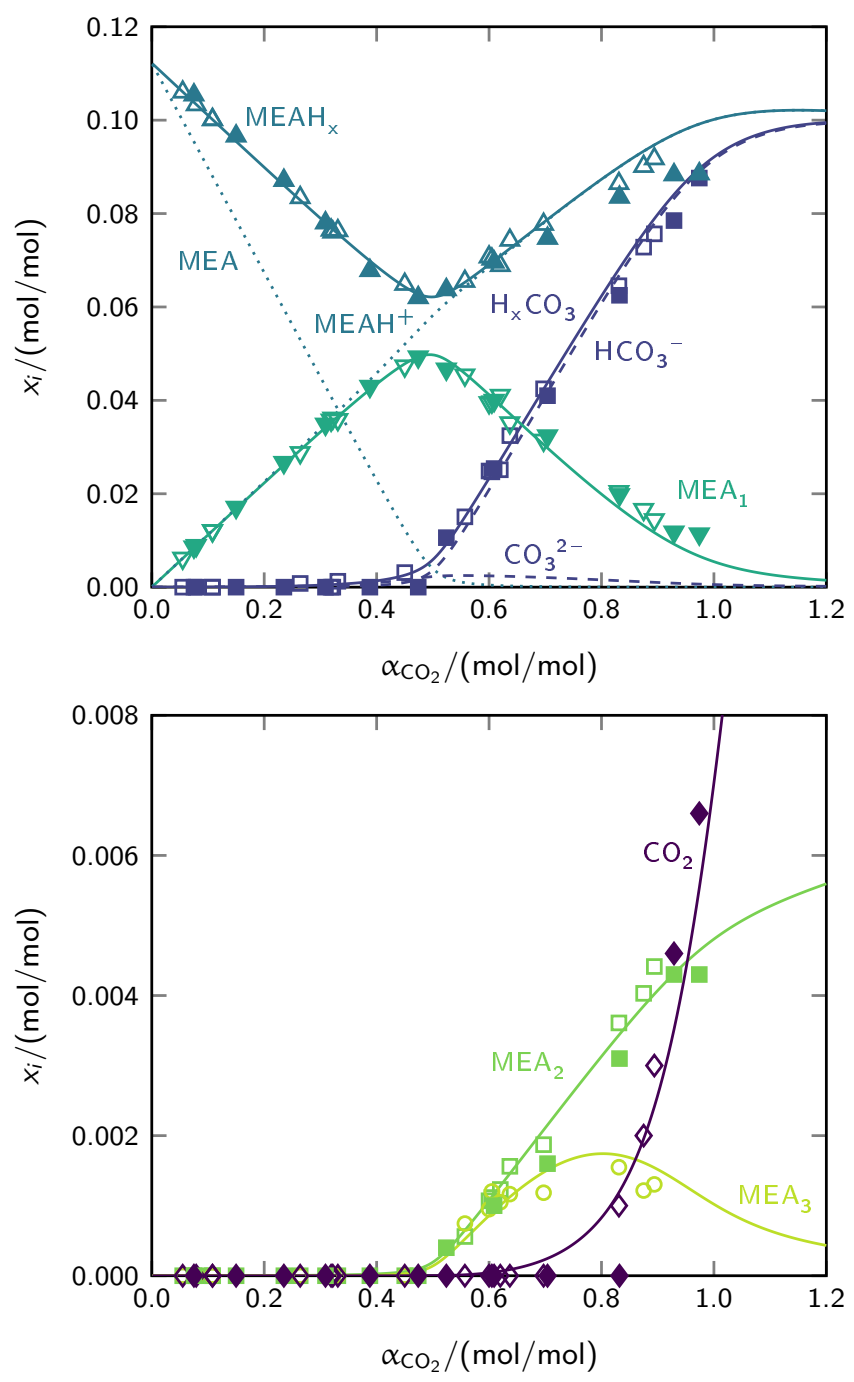

Figure 3: Composition of the liquid phase of the system $\mathrm{MEA}-\mathrm{H}_{2} \mathrm{O}-\mathrm{CO}_{2}$ in chemical equilibrium, for $w_{\mathrm{MEA}}^{0}=0.3 \mathrm{~g} / \mathrm{g}, T=293 \mathrm{~K}$. Open symbols: experimental data from the present work. Filled symbols: experimental data from Böttinger et al. [6]. Lines: model from the present work. 


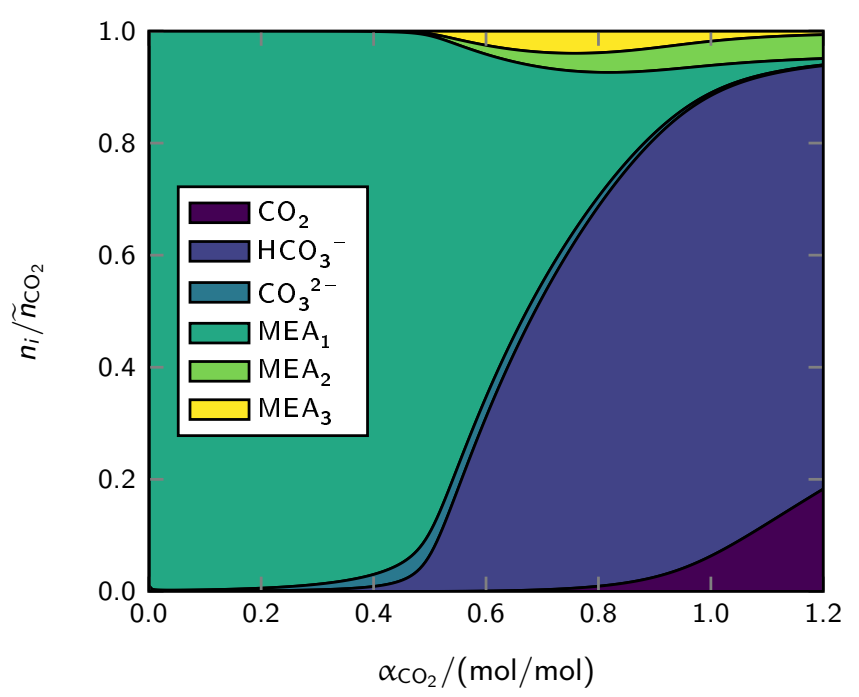

Figure 4: Distribution of the overall $\mathrm{CO}_{2}$ to the different species calculated with the model from the present work, for $w_{\mathrm{MEA}}^{0}=0.3 \mathrm{~g} / \mathrm{g}, T=293 \mathrm{~K}$.

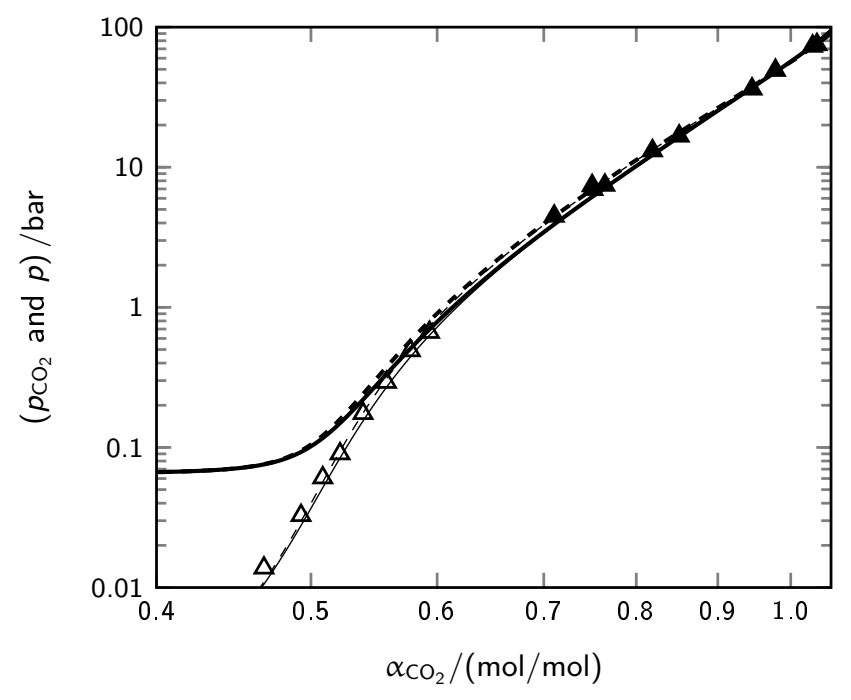

Figure 5: Results from the model from the present work (solid lines) and that of Wagner et al. 9. (dashed lines) for the total pressure (thick lines) and the partial pressure of $\mathrm{CO}_{2}$ (thin lines) above $\mathrm{CO}_{2}$ loaded aqueous solution of MEA, for $w_{\mathrm{MEA}}^{0}=0.3 \mathrm{~g} / \mathrm{g}, T=313 \mathrm{~K}$, Symbols are experimental data from Wagner et al. [9] $\triangle$ : partial pressure $p_{\mathrm{CO}_{2}}$, $\mathbf{\Lambda}$ : total pressure $p$. 


\section{Graphical Abstract}

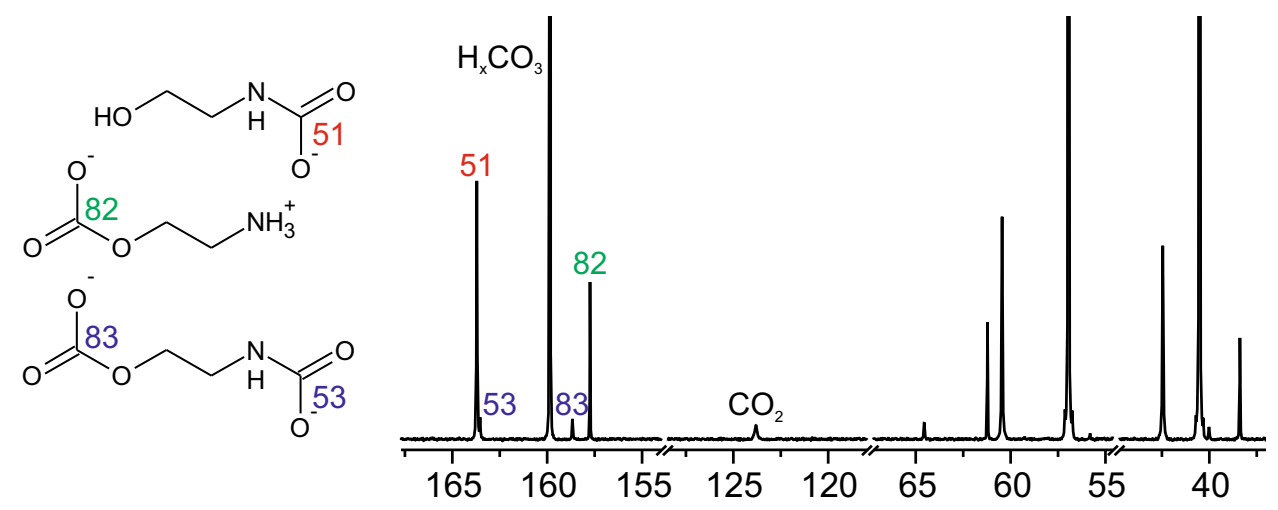

